\title{
Évaluation des risques écologiques causés par des matériaux de dragage: roposition d'une approche adaptée aux dépôts en gravière en eau
}

\section{Ecological risk assessment of dredged materials : a proposed framework for deposits in open gravel quarries}

\author{
M. Babut, Y. Perrodin, M. Bray, B. Clément, C. Delolme, A. Devaux, C. Durrieu, J. \\ Garric, B. Vollat, D. Becart et C. Charrier
}

Volume 15, numéro 3, 2002

URI : https://id.erudit.org/iderudit/705472ar

DOI : https://doi.org/10.7202/705472ar

Aller au sommaire du numéro

Éditeur(s)

Université du Québec - INRS-Eau, Terre et Environnement (INRS-ETE)

ISSN

0992-7158 (imprimé)

1718-8598 (numérique)

Découvrir la revue

Citer cet article

Babut, M., Perrodin, Y., Bray, M., Clément, B., Delolme, C., Devaux, A., Durrieu, C., Garric, J., Vollat, B., Becart, D. \& Charrier, C. (2002). Évaluation des risques écologiques causés par des matériaux de dragage: roposition d'une approche adaptée aux dépôts en gravière en eau. Revue des sciences de l'eau / Journal of Water Science, 15(3), 615-639. https://doi.org/10.7202/705472ar
Résumé de l'article

Une procédure d'évaluation des risques pour l'écosystème aquatique engendrés par un dépôt de matériaux de dragage dans une gravière type a été élaborée, et testée avec des échantillons de sédiments d'un canal du Nord-Est de la France. La procédure comporte une étape d'évaluation sommaire des risques, à partir de quotients des concentrations mesurées par les critères de danger correspondants, et une étape d'évaluation détaillée où des essais de toxicité et de lixiviation en colonnes sont mis en œuvre. Le scénario testé retient trois hypothèses, qui concernent (a) les effets sur les peuplements d'invertébrés benthiques, représentés notamment par Hyalella azteca et Chironomus riparius, (b) les effets sur les peuplements d'organismes pélagiques, représentés par Chlorella vulgaris, Ceriodaphnia dubia, et Brachionus calyciflorus, et (c) la pollution de la nappe alluviale associée. Différentes modalités d'exposition (essais normalisés, microcosmes) ont été testées. Dans le contexte particulier des trois sédiments étudiés, ces hypothèses se sont avérées plus ou moins discriminantes, la pollution de la nappe étant la plus sensible. Des améliorations de la procédure doivent être envisagées qui concernent à la fois la formulation des hypothèses (risques à court et long terme sur les organismes pélagiques), et les protocoles d'essai, tant pour les organismes du sédiment (rôle de la nourriture notamment) que pour les essais de lixiviation en colonnes.
Tous droits réservés ( Revue des sciences de l'eau, 2002
Ce document est protégé par la loi sur le droit d'auteur. L’utilisation des services d'Érudit (y compris la reproduction) est assujettie à sa politique d'utilisation que vous pouvez consulter en ligne.

https://apropos.erudit.org/fr/usagers/politique-dutilisation/ 


\title{
Évaluation des risques écologiques causés par des matériaux de dragage : proposition d'une approche adaptée aux dépôts en gravière en eau
}

\section{Ecological risk assessment of dredged materials: a proposed framework for deposits in open gravel quarries}

\author{
M. BABUT ${ }^{1}{ }^{*}$, Y. PERRODIN $^{2}$, M. BRAY ${ }^{1}$, B. CLÉMENT ${ }^{2}$, C. DELOLME $^{2}$, \\ A. DEVAUX ${ }^{2,5}$, C. DURRIEU ${ }^{2}$, J. GARRIC ${ }^{1}$, B. VOLLAT ${ }^{1}$, D. BÉCART ${ }^{3}$, \\ C. CHARRIER ${ }^{4}$
}

Reçu le 15 octobre 2001, accepté le 21 mai 2002**

SUMMARY

When contaminated by metals or synthetic organic compounds, dredged sediments may have negative impacts on receiving ecosystems. Therefore, there is a need for an operational risk assessment approach. Such a framework is proposed for dredged material deposits in open gravel quarries, which is a rather common means of disposal in France. The first step of the assessment relies upon chemical characterisation of the sediments; the resulting concentrations are divided by "probable effect concentrations" and pooled together, in order to calculate a global hazard quotient. According to the value of this quotient, several decisions can be taken: (a) undertake a detailed risk assessment, (b) dispose of the materials without further constraints, or (c) in case of uncertainty, do some biological testing (with Hyalella azteca and Chironomus riparius) in order to allow decisions. The next step is a detailed ecological risk assessment. Three different assessment endpoints have been proposed, which are (1) the deposit should have no effect on the structure and abundance of benthic invertebrates in the quarry, (2) it should have no long term effect on pelagic species, and (3) it should not cause groundwater pollution, as such quarries are in fact cross sections of shallow alluvial groundwater aquifers. A fourth assessment endpoint should be introduced, regarding health risks for recreational uses, including fishing, but this endpoint was not implemented in the current version of the approach. The analysis phase includes aquatic bioassays (bacteria - Metplate ${ }^{\text {TM}}$-, algae, microcrustaceans Ceriodaphnia dubia, rotifers Brachionus calyciflorus), and leaching assays in columns under ascendant flow.

1. Cemagref, Laboratoire d'écotoxicologie, 3bis, quai Chauveau, CP220, 69336 Lyon cedex 09, France.

2. ENTPE, Laboratoire des sciences de l'environnement, rue Maurice Audin, 69518 Vaulx-en-Velin, France.

3. VNF, service environnement, 2 bd Gambetta, BP53, 60321 Compiègne cedex, France.

4. CETMEF, cellule environnement, 2 bd Gambetta, BP 60039, 60321 Compiègne cedex, France.

5. Inra, département hydrobiologie et faune sauvage, Campus de Beaulieu, 35042 Rennes, France.

* Correspondance. E-mail : marc.babut@cemagref.fr

** Les commentaires seront reçus jusqu'au 30 avril 2003. 
The proposed approach was tested with 3 sediments from a canal located in the north-eastern region of France. Microcosm assays were introduced in parallel to the proposed tests, in order to explore alternatives to standardised bioassays. According to their hazard quotient, the 3 sediments showed a contamination gradient; one of them should not have entered the detailed risk assessment phase, while another would have been further tested with $H$. azteca and $C$. riparius. In that case, this latter sediment would not have entered the detailed phase either, as it was not toxic to these species. However, the detailed risk assessment approach was applied to the three sediments, so as to test completely the relevance of the framework.

The three sediments were not significantly toxic to either $C$. riparius or $H$. azteca. However, some effects were observed in microcosms, including genotoxicity to molluscs. In this case, no risk characterisation could be made. Pore waters extracted from the three sediments were not toxic or slightly toxic to bacteria, algae, and $C$. dubia; an EC10 value could be determined only for $B$. calyciflorus. Therefore, due to exposure calculations, it seems there is a risk to pelagic species. However, as 3 bioassays out of 4 were negative or inconclusive, a refinement step would seem to be necessary. The highest concentrations of cadmium, copper, chromium, nickel and zinc were measured in the first lixiviates of the most contaminated sediment. Yet, even in that case, the total extracted fraction remained less than $10 \%$ of the total load. This fraction was below $1 \%$ for the other sediments, whatever the metal. Maximum concentrations and predicted concentrations at 1 year were compared to drinking water standards. This comparison showed a real risk of degrading groundwater quality for that most contaminated sediment, and a transient risk due to cadmium and nickel for the following one on the contamination gradient.

Considering these results, the design of the first step of the proposed assessment approach may be discussed, as one sediment which would not have been assessed in depth according to its hazard quotient did show a risk to pelagic species. This discrepancy underlines the fact that some sediment toxicity may exist below the lowest threshold. As it would be unrealistic to enter systematically into detailed risk assessments, the proposed thresholds in the decision diagram must be pragmatic compromises rather than absolutely safe boundaries. Moreover, protocol improvements are needed for sediment toxicity bioassays. Chronic endpoints are preferable, as they are more sensitive and more relevant. Another issue is related to the role of additional food: not adding food may increase the apparent toxicity, but the sediment organic content, which is an alternative food source, may also be a contaminant carrier. Furthermore, the second assessment endpoint (risk to pelagic species) should be reformulated, as it includes in fact two different questions. Shortterm risks related to the deposition phase could be assessed with standardised bioassays like $C$. dubia survival and reproduction and algal growth, while longer term risks related to contaminant diffusion could be assessed with microcosms. Genotoxic effects were observed at rather high levels, as compared to published results. This result stresses the interest of introducing sensitive and early markers in the risk assessment process, although their real meaning for ecosystems is not yet fully elucidated. Finally, the leaching tests in columns are not completely satisfactory, as the column filling implies that one must first dry the sediments, which will alter their structure. Other application trials along with field validation studies should be carried out prior to the introduction of this scenario in operational or regulatory frameworks.

Key-words: sediment, dredging, ecological risk assessment, risk quotient, bioassay, microcosm, percolation. 


\section{RÉSUMÉ}

Une procédure d'évaluation des risques pour l'écosystème aquatique engendrés par un dépôt de matériaux de dragage dans une gravière type a été élaborée, et testée avec des échantillons de sédiments d'un canal du Nord-Est de la France. La procédure comporte une étape d'évaluation sommaire des risques, à partir de quotients des concentrations mesurées par les critères de danger correspondants, et une étape d'évaluation détaillée où des essais de toxicité et de lixiviation en colonnes sont mis en ouvre. Le scénario testé retient trois hypothèses, qui concernent (a) les effets sur les peuplements d'invertébrés benthiques, représentés notamment par Hyalella azteca et $\mathrm{Chi}$ ronomus riparius, (b) les effets sur les peuplements d'organismes pélagiques, représentés par Chlorella vulgaris, Ceriodaphnia dubia, et Brachionus calyciflorus, et (c) la pollution de la nappe alluviale associée. Différentes modalités d'exposition (essais normalisés, microcosmes) ont été testées. Dans le contexte particulier des trois sédiments étudiés, ces hypothèses se sont avérées plus ou moins discriminantes, la pollution de la nappe étant la plus sensible. Des améliorations de la procédure doivent être envisagées qui concernent à la fois la formulation des hypothèses (risques à court et long terme sur les organismes pélagiques), et les protocoles d'essai, tant pour les organismes du sédiment (rôle de la nourriture notamment) que pour les essais de lixiviation en colonnes.

Mots clés : sédiment, dragage, évaluation de risque, quotient de risque, bioessai, microcosme, percolation.

\section{1 - INTRODUCTION}

Parmi les substances chimiques rejetées dans l'environnement, nombre d'entre elles s'accumulent dans les vases ou boues constituant les sédiments, au fond des rivières et lacs ainsi que dans les estuaires et les fonds marins. Beaucoup des sédiments contaminés ont été pollués il y a des années, par des substances aujourd'hui souvent quasi absentes des eaux superficielles. Leur persistance parfois à très long terme dans les sédiments peut entraîner des effets néfastes tant pour l'écosystème que pour la santé humaine. Les dégâts écologiques et sanitaires causés par la contamination des sédiments ont un coût social réel : il s'agit de la diminution de la diversité des communautés, en particulier d'invertébrés, av зc des conséquences indirectes sur les peuplements de poissons, ou de la perte de comestibilité des poissons ou des coquillages, ou encore des usages récréatifs affectés ou impossibles, ainsi que des coûts supplémentaires liés à la gestion des matériaux contaminés lors d'opérations de dragage ou de curage (EPA, 1997a). Les contaminants les plus fréquemment cités sont des métaux (cadmium, chrome, cuivre, mercure, nickel, plomb et zinc), l'arsenic, les PCBs et les hydrocarbures polycycliques aromatiques (HAP) (BABUT et al., 1999 ; EPA, 1997b).

Les dépôts de sédiments, contaminés ou non, peuvent induire des besoins de curage, lorsqu'ils augmentent le risque d'inondation, ou diminuent le tirant d'eau des parties navigables (IMBERT et DUCHENE, 1998). Les problèmes de contamination des matériaux extraits, rencontrés par tous les pays industrialisés, ont suscité la mise au point de procédures et de méthodes d'évaluation 
des dangers ou des risques, permettant ensuite la prise de décisions de gestion (cf. notamment IMBERT et DUCHENE, 1998 ; US-EPA et USACE, 1994, 1998a, b). Dans cet esprit, il est apparu souhaitable d'évaluer dans le contexte français des scénarios correspondant à des modes répandus de gestion des matériaux de dragage. Par scénario, on entend ici un ensemble cohérent d'informations incluant la description de la procédure de gestion des matériaux de dragage, du site de stockage éventuel, et des impacts potentiels sur l'écosystème (cf. ci-dessous "formulation du problème "). Ces scénarios doivent permettre de standardiser la démarche opérationnelle d'évaluation des risques pour l'écosystème à appliquer lors d'opérations de dragage. Le présent article rend compte du développement d'un scénario « dépôt dans une gravière en eau ". Ce scénario a été utilisé pour mener une évaluation des risques pour l'écosystème dans le cas de sédiments d'un canal du Nord-Est de la France.

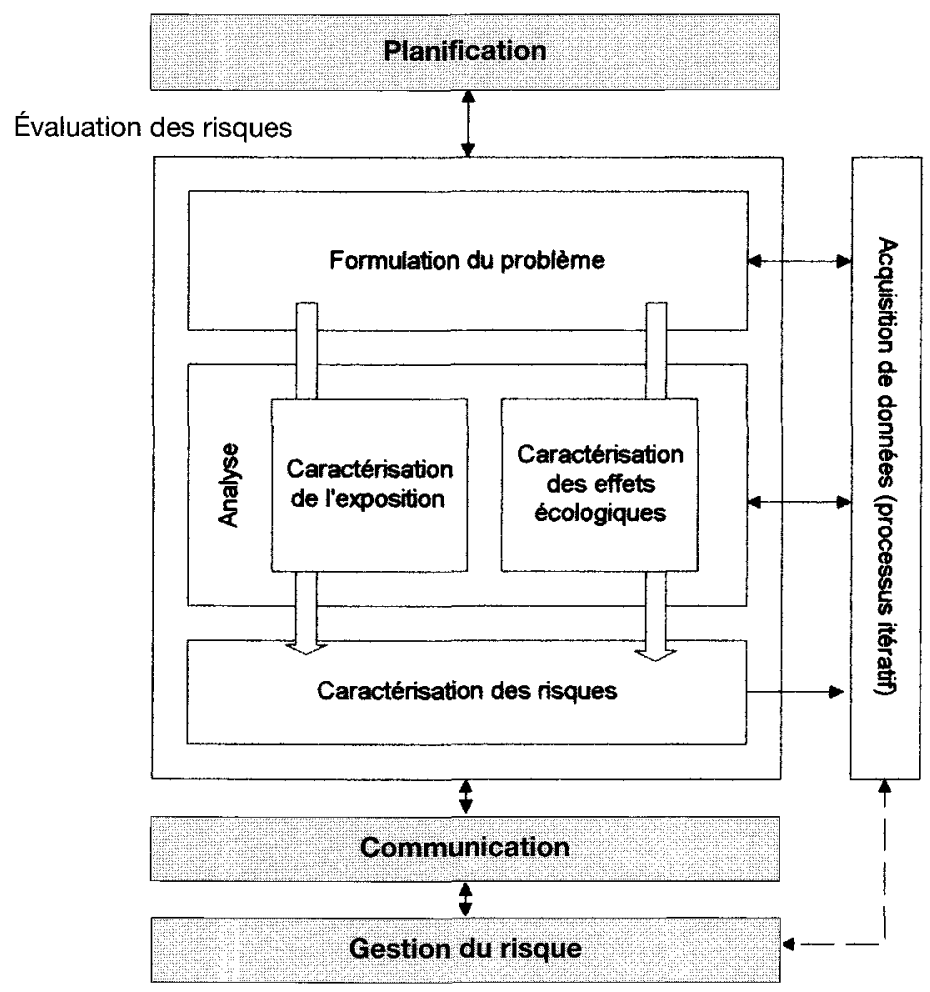

Figure 1 Cadre général de l'évaluation des risques pour l'écosystème.

The ecological risk assessment framework.

\section{2 - DÉMARCHE D'ÉVALUATION DES RISQUES ÉCOLOGIQUES}

\subsection{Principe général}

Le schéma général proposé par l'EPA (1998) comporte trois parties (figure 1) : 
- la formulation du problème, qui vise à élaborer un modèle conceptuel et un plan d'analyse et définir les moyens à mettre en œuvre pour caractériser le risque ;

- l'analyse proprement dite, où l'on collecte les données nécessaires à l'évaluation des effets et de l'exposition;

- la caractérisation des risques, où l'on estime le(s) risque(s) et, autant que possible, les incertitudes associées.

La formulation du problème est une étape critique, dont l'objectif est de détailler le cahier des charges des phases d'analyse et de caractérisation, en identifiant précisément les données à acquérir, les techniques de mesure ou d'évaluation et le cadre d'interprétation. Cette étape comprend essentiellement trois éléments :

- la description détaillée du contexte et l'intégration des données disponibles :

- la sélection des “paramètres d'évaluation » et l'élaboration du modèle conceptuel ;

- l'élaboration d'un plan d'analyse.

\subsection{Application au dépôt de matériaux de dragage dans une gravière en eau}

La gestion des matériaux de dragage en eau douce est actuellement en France une activité dont l'encadrement réglementaire est complexe, et encore sujet à discussion (IMBERT et DUCHENE, 1998). Une fois retirés du milieu aquatique, ces matériaux sont assimilables à des déchets, mais leur réintroduction dans le milieu aquatique renvoie à l'application de la loi sur l'eau (loi $n^{\circ} 92-3 \mathrm{du}$ 3 janvier 1992 sur l'eau, Journal Officiel du 4 janvier 1992). Face à cette complexité, les organismes gestionnaires sont demandeurs d'une méthodologie apte à guider la conduite des opérations. Nous proposons en réponse une démarche progressive, décrite ci-après. Le cadre général comporte trois étapes (figure 2) : la première est assimilable à une évaluation sommaire des risques, faite principalement à partir de la caractérisation chimique des sédiments, la deuxième à un affinement de cette évaluation sommaire, la troisième à une évaluation détaillée des risques.

Évaluation sommaire : pour un site donné, et un contaminant particulier, le risque est représenté par le rapport entre la concentration totale de ce polluant et un " seuil d'effet probable " (PEC), tiré de la littérature (MACDONALD et al., $2000 \mathrm{~b}$ ). Ces quotients individuels peuvent être agrégés pour représenter le risque global du site ou du sédiment considéré :

$$
Q_{P E C m}=\frac{\sum_{i=1}^{n} \frac{C i}{P E C i}}{n}
$$

avec $C i$ : concentration mesurée pour le paramètre i ;

$P E C i$ : concentration seuil d'effet probable $; n$ : nombre de paramètres mesurés. 


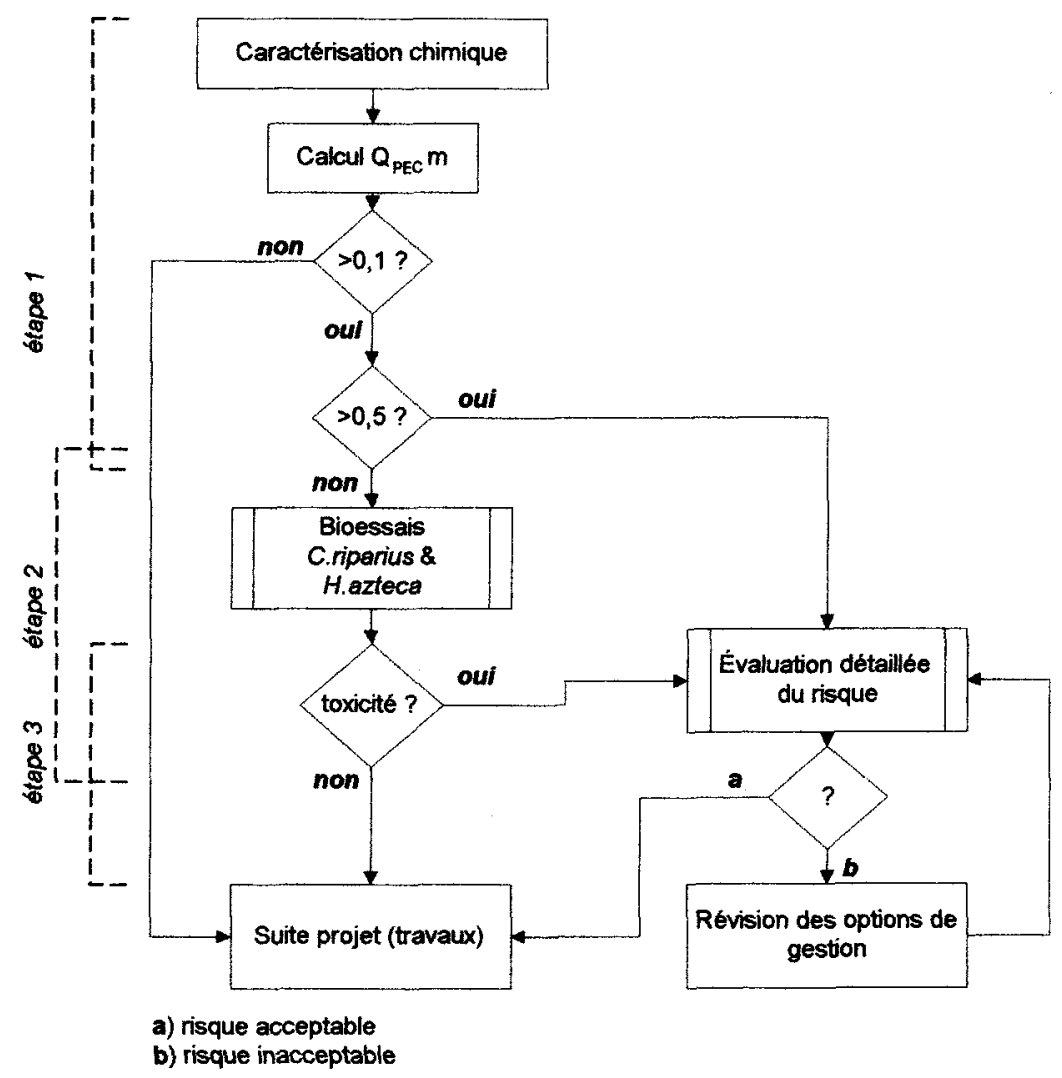

Figure 2 Logigramme de la démarche d'évaluation en deux étapes.

Flow-diagram of the 2-tiered assessment process.

MACDONALD et al. (2000b) ont montré qu'il y avait une corrélation entre la somme des quotients individuels divisée par le nombre de contaminants mesurés $\left(Q_{P E C m}\right)$ et le pourcentage d'échantillons toxiques dans un jeu de données incluant plusieurs centaines de sédiments. Pour des valeurs de $Q_{P E C m}$ inférieures à 0,1 ils considèrent que la probabilité d'observer des effets toxiques est réduite, et qu'elle est forte au-dessus de 0,5.

De ce fait, pour réaliser cette évaluation préliminaire, nous proposons de considérer la valeur de 0,1 comme un seuil au-dessous duquel les risques sont négligeables, les matériaux dragués pouvant alors être éliminés sans contrainte particulière. En revanche, pour $\mathrm{Q}_{\mathrm{PECm}}>0,5$, il conviendrait de passer à l'étape d'évaluation détaillée des risques. Pour les valeurs de $Q_{P E C m}$ comprises entre 0,1 et 0,5 , des essais de toxicité complémentaires permettraient de décider s'il faut passer à l'étape d'évaluation détaillée ou non.

Cette étape d'évaluation préalable est applicable dans d'autres scénarios, par exemple un dépôt non confiné sur sol. 


\subsection{Formulation du problème pour l'évaluation détaillée des risques écologiques}

\subsubsection{Description du contexte}

La gravière en eau se présente de fait comme une enclave de la nappe alluviale, comportant une surface libre. Le dépôt se fait à partir de l'aval vers l'amont (CALLIER et CHARBONNIER, 2000). Si la réglementation en vigueur en France pour ce type de dépôt précise que seuls les matériaux inertes sont autorisés, elle n'indique pas en revanche comment déterminer cette propriété.

Dans le scénario type, on considère un écosystème associé à la gravière comportant trois niveaux trophiques (producteurs primaires, consommateurs primaires et consommateurs secondaires).

Les contaminants contenus dans les matériaux déposés sont ceux identifiés à l'étape préliminaire de caractérisation, auxquels s'ajoutent des constituants naturels des sédiments comme l'ammoniaque (GARRIC et al., 1990) ou le manganèse (LASIER et al., 2000). Ils peuvent :

- être libérés au moment même du dépôt ;

- après désorption, être entraînés par convection-dispersion vers la nappe alluviale ;

- être transformés selon des processus biotiques ou abiotiques.

D'autres voies de transfert telles que la diffusion vers la colonne d'eau après désorption, ou le transport de particules fines, sont possibles. Elles n'ont toutefois pas été prises en considération jusqu'à présent, en raison de l'absence d'éléments sur leur importance relative, et faute de pouvoir les tester expérimentalement dans un cadre opérationnel.

L'exposition des organismes peut s'envisager au niveau de la colonne d'eau, ou lors de contacts avec le dépôt. Le scénario étudié conduit donc à s'intéresser à ces deux milieux : d'une part le sédiment déposé dans son entier qui pourrait affecter les organismes en place, ou limiter la recolonisation en raison de sa médiocre qualité, d'autre part l'eau interstitielle, susceptible de se mélanger à l'eau de la gravière au moment du dépôt.

\subsubsection{Modèle conceptuel}

Dans le scénario proposé, en l'absence d'indication précise sur les usages, la protection générale des espèces susceptibles d'être présentes, et la préservation de pratiques comme la pêche doivent être considérées. Ce scénario peut être adapté cas par cas si besoin. On en déduit les bases d'évaluation suivantes :

1. le dépôt de sédiment en gravière ne devra pas perturber la structure et les effectifs des peuplements d'invertébrés benthiques ;

2. il ne devra pas entraîner d'effets à long terme sur les espèces vivant dans la colonne d'eau ;

3. il ne devra pas engendrer de risque pour la santé des usagers du plan d'eau, notamment les pêcheurs ;

4. enfin, il ne devra pas entraîner de pollution de la nappe alluviale, en particulier dans la perspective de son utilisation pour la production d'eau potable. 
Dans l'état actuel de développement de la méthodologie, seules les hypothèses dérivées des points 1,2 et 4 sont testées. Le modèle conceptuel découlant de la description du contexte et de ces choix est représenté par la figure 3. De façon à ce que les hypothèses à tester puissent être abordées avec des méthodes d'essai aussi standardisées que possible, les peuplements d'invertébrés benthiques sont représentés par une larve d'insecte (Chironomus riparius) et un crustacé épibenthique (Hyalella azteca) ainsi que par les bactéries. Les espèces de la colonne d'eau sont représentées par les algues (Chlorella vulgaris) et un microcrustacé pélagique (Ceriodaphnia dubia). Ces choix opérationnels n'interdisent pas de compléter les expérimentations en introduisant d'autres organismes. Les paramètres mesurés incluent essentiellement la survie, la croissance et la reproduction. L'objectif poursuivi en choisissant ces organismes et ces paramètres est la protection de l'écosystème. Cet objectif est considéré atteint si la reproduction (ou à court terme la survie) de peuplements représentés par ces quelques espèces est assurée. Le transfert de polluants vers la nappe est étudié à l'aide d'essais de percolation en colonnes de sédiments.

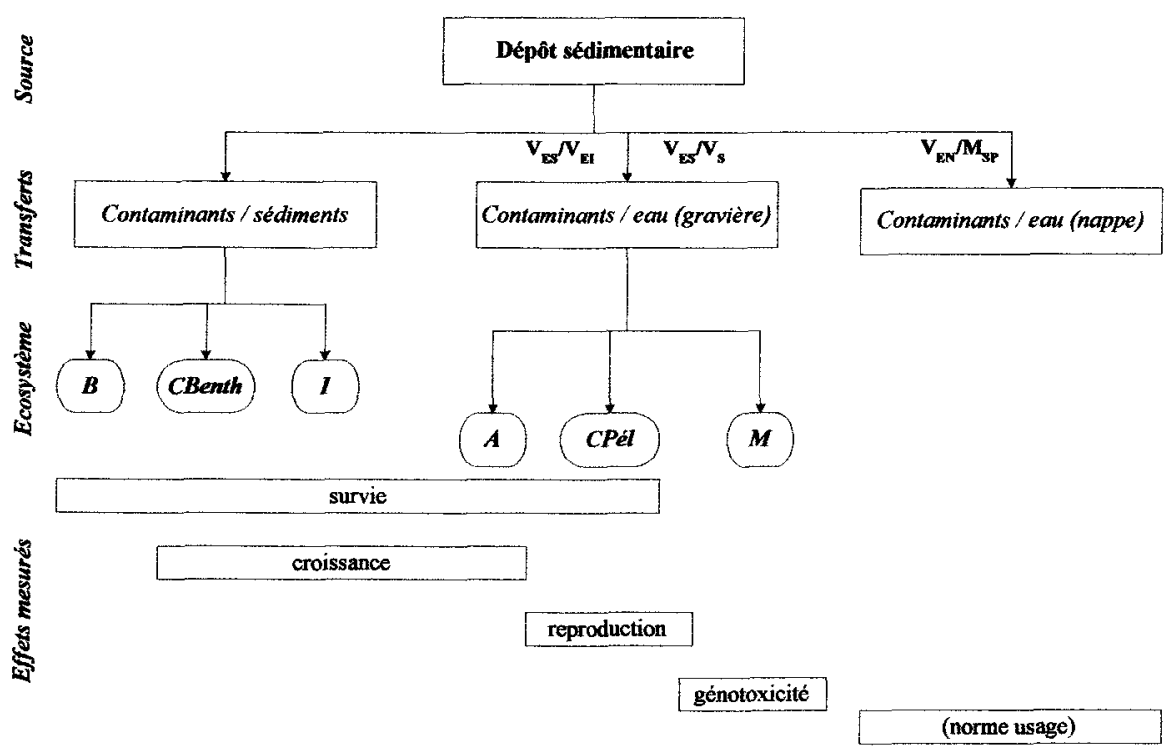

Figure 3 Modèle conceptuel de l'évaluation des risques pour l'écosystème dans le cas d'un dépôt en gravière.

$B$ : bactéries ; $C$ Benth : crustacés benthiques ; $I$ : insectes ; $A$ : algues ; $C$ Pél: crustacés pélagiques; $M$ : mollusques.

Conceptual model for the ecological risk assessment in case of a dredged material deposit in open gravel quarries.

Les niveaux d'exposition des organismes peuvent être estimés à l'aide de différents ratios entre des descripteurs du sédiment dragué d'une part, de la gravière d'autre part. Le ratio "volume eau de surface/volume de sédiments" $\left(V_{E S} N_{S}\right)$ caractérise l'importance relative du dépôt dans la gravière. Le ratio « volume eau de surface/volume d'eau interstitielle libérée des sédiments" 
$\left(V_{E S} N_{E I}\right)$ détermine l'exposition des espèces de la colonne d'eau au moment du dépôt, en faisant l'hypothèse que la totalité de l'eau interstitielle libérable se mélange à l'eau de la gravière. Le ratio annuel " volume eau de nappe/masse brute de sédiment traversé par percolation " $\left(V_{E N} / M_{S P}\right)$ permet de calculer les concentrations de contaminants dans la nappe. La connaissance de ces ratios, ou au moins une estimation moyenne raisonnable, est indispensable, d'une part pour déterminer les gammes de concentrations à tester pendant la phase d'analyse, d'autre part pour la caractérisation du risque.

II est clair que cette représentation de l'écosystème et des interactions entre les organismes est très fortement simplifiée. Elle correspond à des données aisément disponibles et s'appuie principalement sur des essais écotoxicologiques standardisés, ou en développement mais potentiellement standardisables. La pertinence de cette représentation se vérifiera in fine par la qualité des résultats, c'est-à-dire le maintien de la qualité des écosystèmes concernés en présence de dépôts effectivement réalisés.

\section{3 - MATÉRIEL ET MÉTHODES}

La démarche décrite ci-dessus a été appliquée à trois lots de sédiments provenant de trois biefs, numérotés 2, 13 et 22, du canal de l'Est branche sud (CEBS) dans le département des Vosges. Les méthodes résumées ci-après se réfèrent à l'étape d'évaluation détaillée, à l'exception des analyses de contaminants, dont les résultats peuvent être utilisés aussi bien au cours de l'évaluation sommaire que dans l'évaluation détaillée.

\subsection{Détermination des ratios caractéristiques de l'exposition}

- $\mathrm{V}_{\mathrm{ES}} / \mathrm{V}_{\mathrm{S}}$ : le premier terme (volume d'eau de surface) correspond au produit de la superficie de la gravière par la hauteur d'eau moyenne dans la gravière. Le deuxième terme (volume de sédiment déposé) est fourni par le maître d'ouvrage de l'opération. Ce ratio sert notamment à définir les conditions de mise en œuvre des essais en microcosmes.

- $\mathrm{V}_{\mathrm{ES}} \mathrm{N}_{\mathrm{El}}$ : Le premier terme est le même que dans le ratio précédent. Le deuxième terme est le produit de la teneur en eau interstitielle du sédiment, par le volume de matériau dragué. La teneur en eau interstitielle se déduit du volume d'eau récupéré par centrifugation sur un échantillon moyen de sédiment.

- $V_{E N} / M_{S P}$ : le premier terme résulte du produit de la vitesse de la nappe alluviale ( $\mathrm{m} / \mathrm{an})$ traversant la gravière et percolant à travers le dépôt, par la section de celui-ci $\left(\mathrm{m}^{2}\right)$. Le deuxième terme peut être estimé en multipliant le volume de sédiment déposé par sa densité, estimée à 1,2. La connaissance de ce ratio permet de fixer les conditions opératoires des essais de percolation en colonne.

Les gravières susceptibles d'être utilisées pour déposer les matériaux du CEBS n'étant pas encore identifiées et caractérisées au moment de cette 
étude, nous avons travaillé sur une gravière fictive de superficie $2500 \mathrm{~m}^{2}(50 \mathrm{~m}$ $\times 50 \mathrm{~m}$ ), et de $10 \mathrm{~m}$ de profondeur, avec un dépôt de sédiment sur $2 \mathrm{~m}$ de hauteur. La vitesse de la nappe alluviale a été fixée à $100 \mathrm{~m} / \mathrm{an}$, ce qui est une vitesse moyenne (CASTANY, 1982). Dans ces conditions, les ratios $V_{E S} / V_{S}$, $V_{E S} N_{E l}$ et $V_{E N} / M_{S P}$ valent respectivement 5,25 et 1,5 .

\subsection{Prélèvement, transport et conservation des échantillons}

Les prélèvements ont été faits les 9 et 10 mai 2000 à la drague, la couche est prélevée sur une hauteur d'environ $10 \mathrm{~cm}$, jusqu'à obtention de 180 litres de sédiment frais par bief, répartis dans trois récipients. Au laboratoire, l'eau de ressuyage est recueillie par siphonnage ; elle n'est pas testée dans le cadre de ce scénario. Le sédiment est ensuite homogénéisé puis reconditionné en bocaux et conteneurs. L'eau interstitielle est produite par centrifugation (4000 g pendant $10 \mathrm{~min}$ à $4^{\circ} \mathrm{C}$ ). L'ensemble de ces manipulations a été effectué 5 jours après les prélèvements ; dans l'intervalle, les échantillons ont été conservés en chambre froide à $4{ }^{\circ} \mathrm{C}$.

\subsection{Colonnes de percolation}

Le matériau, séché à $50^{\circ} \mathrm{C}$ pendant une durée de $96 \mathrm{~h}$ à $120 \mathrm{~h}$ et tamisé à un centimètre, est introduit dans des colonnes PVC $(\varnothing=15 \mathrm{~cm}, \mathrm{~h}=10 \mathrm{~cm})$. Le remplissage de la colonne s'effectue en cinq fois avec une louche et un compactage léger grâce à une dame pour homogénéiser, jusqu'à obtention d'une densité sèche apparente de l'ordre de 1 à 1,2. La solution de saturation et de lixiviation est constituée par de l'eau de composition minéralogique proche de la nappe alluviale traversant la gravière. La saturation en eau de la colonne est obtenue avec une bouteille de Mariotte en introduisant l'eau par le bas de la colonne, et en maintenant le contact pendant une durée de 24 heures. Un flux d'eau est ensuite introduit en continu de manière ascendante dans la colonne, à un débit constant de $2 \mathrm{~mL} \cdot \mathrm{min}^{-1}$. Ce débit représente une vitesse d'infiltration (ou vitesse de Darcy) de $16,3 \mathrm{~cm} \cdot \mathrm{jr}^{-1}\left(60 \mathrm{~m} \cdot \mathrm{an}^{-1}\right)$. La durée de la percolation est fixée par le ratio cumulé L/S (volume de liquide ayant traversé la colonne / poids sec de l'échantillon dans la colonne) et par le débit de la pompe. L'expérience est arrêtée une fois atteint un ratio cumulé $L / S$ plusieurs fois supérieur à la valeur annuelle, soit dans le cas présent égal à 10 (projet CENT/TC92/WG6/N151). Cette valeur correspond à 8 jours de percolation dans les conditions de débit retenues. Des échantillons de percolat sont récupérés en continu grâce à un collecteur de fractions, chaque fois que le ratio L/S est incrémenté de 0,1 , de façon à suivre l'évolution des paramètres $(\mathrm{pH}$, conductivité, COT, teneur en métaux...) en fonction du ratio L/S cumulé. L'utilisation du ratio L/S permet alors de comparer les cas entre eux. Les essais ont été réalisés sans réplication, en raison d'une quantité de matériau insuffisante.

\subsection{Bioessais}

Autant que possible, la méthodologie fait appel à des bioessais normalisés, ou standardisés. Ces bioessais sont listés au tableau 1. S'agissant de protocoles normalisés ou standardisés, ils ne seront donc pas détaillés ici. Les Cl10 sont obtenues par régression log-logistique, les intervalles de confiance étant déterminés par rééchantillonnage de type bootstrap (ISNARD et al., 2001). 
Tableau 1 Bioessais utilisés.

Table 1 Bioassays used in the scenario.

\begin{tabular}{|c|c|c|c|c|c|}
\hline Organisme & Durée & Effet & Paramètre & Protocole & Référence \\
\hline \multicolumn{6}{|l|}{$\begin{array}{l}\text { Organismes } \\
\text { de la colonne } \\
\text { d'eau }\end{array}$} \\
\hline $\begin{array}{l}\text { Escherichia } \\
\text { coli }\end{array}$ & $1 \mathrm{~h} 30$ & $\begin{array}{l}\text { Inhibition de } \\
\text { l'activité } \beta- \\
\text { galactosidase }\end{array}$ & CE50 & MetPlate TM & BITTON G. et al. (1993) \\
\hline $\begin{array}{l}\text { Chlorella } \\
\text { vulgaris }\end{array}$ & 5 jours & Croissance & $\begin{array}{l}\text { CE50, CE10, } \\
\text { NOEC }\end{array}$ & Standardisé & $\begin{array}{l}\text { D'après Afnor T 90-304 } \\
\text { (adaptée à une } \\
\text { réalisation } \\
\text { en microplaques, } \\
\text { espèce différente) }\end{array}$ \\
\hline $\begin{array}{l}\text { Ceriodaphnia } \\
\text { dubia }\end{array}$ & $\begin{array}{l}48 \text { heures } \\
7 \text { jours }\end{array}$ & $\begin{array}{l}\text { Survie } \\
\text { Reproduction }\end{array}$ & $\begin{array}{l}\text { Cl50 } \\
\text { CE10, NOEC }\end{array}$ & $\begin{array}{l}\text { Normalisé } \\
\text { Normalisé }\end{array}$ & $\begin{array}{l}\text { EPA } 1002.0 \\
\text { Afnor T } 90376\end{array}$ \\
\hline $\begin{array}{l}\text { Brachionus } \\
\text { calyciflorus }\end{array}$ & $\begin{array}{l}24 \text { heures } \\
48 \text { heures }\end{array}$ & $\begin{array}{l}\text { Survie } \\
\text { Reproduction }\end{array}$ & $\begin{array}{l}\text { Cl50 } \\
\text { CE10, NOEC }\end{array}$ & $\begin{array}{l}\text { Normalisé } \\
\text { Normalisé }\end{array}$ & Afnor T 90-377 \\
\hline \multicolumn{6}{|l|}{$\begin{array}{l}\text { Organismes } \\
\text { du sédiment }\end{array}$} \\
\hline Hyalella azteca & 14 jours & $\begin{array}{l}\text { Survie, } \\
\text { croissance }\end{array}$ & & Standardisé & d'après EPA (1994) \\
\hline $\begin{array}{l}\text { Chironomus } \\
\text { riparius }\end{array}$ & 10 jours & $\begin{array}{l}\text { Survie, } \\
\text { croissance }\end{array}$ & & Standardisé & d'après EPA (1994) \\
\hline
\end{tabular}

\subsection{Essais en microcosmes}

Ces essais ont été introduits à titre exploratoire, puisqu'ils ne répondent pas au critère de standardisation. Les microcosmes consistent en des béchers de 2 litres contenant environ $300 \mathrm{~g}$ de sédiment à tester, surmontés d'une colonne d'eau (CLEMENT et CADIER, 1998). Les témoins contiennent un sédiment artificiel constitué de sable (65\%), de kaolin (30\%) et de matière organique (cellulose, $4,85 \%$ et nourriture pour poissons $0,15 \%$ ). À l'exception de l'espèce d'algue, ces microcosmes contiennent les mêmes organismes pélagiques (crustacés Daphnia magna, algues Pseudokirchneriella subcapitata, macrophytes Lemna minor) et benthiques (diptères Chironomus riparius, crustacés Hyalella azteca) que ceux des essais normalisés. Ces organismes sont ajoutés en début d'essai, après mise en place du système eau/sédiment. L'introduction des organismes issus de cultures et d'élevages débute 3 à 4 jours après mise en eau des microcosmes : $10 \mathrm{D}$. magna âgées de 1 à 3 jours, 13000 à 16000 cellules $/ \mathrm{mL}$ de $P$. subcapitata, 3 colonies de 2 frondes de $L$. minor, $10 \mathrm{H}$. azteca âgés de 2 à 4 semaines, 25 larves de $C$. riparius âgées de 4 jours maximum après éclosion ( $1^{\text {er }}$ stade). Un suivi des populations est effectué sur 28 jours (comptage et poids des amphipodes survivants, comptage et poids des larves de chironomes survivantes, émergence des chironomes à partir de la deuxième semaine). Le suivi physicochimique des microcosmes porte sur l'oxygène dissous, le $\mathrm{pH}$, la conductivité, le potentiel rédox et les nutriments. Le nombre de réplicats dépend du nombre d'observations réalisées pendant la période de 28 jours : pour 4 observations à J7, J14, J21 et J28, il faut 12 béchers d'essais par sédiment testé et 12 témoins. 
Des limnées (Limnea stagnalis) sont ajoutées aux microcosmes en même temps que les autres organismes, à raison de 3 individus par bécher. À chaque intervalle d'observation (J7, J14 etc.), la mortalité dans les microcosmes sacrifiés est notée, 50 à $100 \mu \mathrm{L}$ d'hémocytes des survivants sont prélevés pour réaliser un essai des comètes en conditions alcalines afin d'évaluer la pression génotoxique en termes de cassures simple et double brin de l'ADN suivant le protocole décrit par SINGH et al. (1988). Ce dernier fait actuellement l'objet d'une procédure de normalisation internationale (TICE et al., 2000).

\subsection{Analyses}

Les analyses ont été réalisées pour partie au Laboratoire départemental d'analyses de la Drôme, selon les protocoles suivants. Pour les PCB et HAP, extraction selon la méthode US-EPA 3545, puis CPG détection ECD selon la norme NF EN ISO 6468, ou HPLC-fluorimétrie, confirmation par CPG-SM selon la norme NF ISO 13877. Quant à l'As, méthode NF EN ISO 11885 (mars 1998). Enfin le $\mathrm{Hg}$ a été analysé selon la méthode NF EN 1483 (juillet 1997).

Les analyses des autres éléments-traces dans les sédiments et l'eau ont été réalisées au Laboratoire des sciences de l'environnement de l'École nationale des travaux publics de l'État (Vaulx-en-Velin) suivant la norme NF X31151. Après minéralisation à l'acide fluorhydrique et nitrique, le dosage des métaux est effectué par spectrométrie d'absorption atomique (SAA, Itachi). Les métaux des échantillons liquides (eaux d'égouttage et eaux interstitielles) sont dosés par SAA après acidification de l'échantillon à l'acide nitrique ultra pur $(\mathrm{pH}<2)$. Les dosages de traces (concentrations inférieures au $\mathrm{mg} \cdot \mathrm{L}^{-1}$ ) sont réalisés au four. Pour les éléments les plus concentrés, l'analyse se fait à la flamme.

\section{4 - RÉSULTATS}

\section{1 Étape 1 : estimation sommaire du risque}

Les caractéristiques physicochimiques des sédiments des biefs 2,13 et 22 sont résumées au tableau 2. Ces sédiments apparaissent comme modérément contaminés par rapport aux gammes de concentrations citées dans la littérature (cf. par exemple EPA 1997b ; KEMBLE et al., 1998) et notamment celles utilisées pour établir les PEC (MACDONALD et al., 2000a ; MACDONALD et al., 2000b). Le sédiment du bief 13 est le plus chargé en éléments-traces minéraux, en particulier en cuivre, plomb, cadmium et zinc. Les $Q_{\text {PECm }}$ calculés selon l'équation 1 valent respectivement $0,198,1,250$ et 0,437 . L'application stricto sensu du schéma résumé figure 2 conduirait donc à ne retenir que le bief 13 pour l'étape d'évaluation détaillée. Celle-ci a cependant été conduite sur les trois échantillons, de façon à obtenir une première vérification de la pertinence des propositions. 
Tableau 2 Caractéristiques physicochimiques des sédiments des trois biefs (en $\left.\mathrm{mg} \cdot \mathrm{kg}^{-1}\right)$.

Table 2 Physico-chemical characterisation of the 3 studied sediments.

\begin{tabular}{|l|c|c|c|}
\hline Bief & $\mathbf{3}$ & $\mathbf{1 3}$ & $\mathbf{2 2}$ \\
\hline Teneur en eau (\%) & 50,1 & 64,6 & 61,9 \\
Fraction < $50 \mu \mathrm{m}(\%)$ & 70,4 & 65,1 & 42,9 \\
Matière organique (\% matières sèches) & $\mathbf{9}$ & 16 & 12 \\
Arsenic & 22,9 & 31,9 & 21,2 \\
Cadmium & 0,5 & 7,8 & 4,8 \\
Chrome & 18,5 & 1,9 & 22,2 \\
Cuivre & 24,7 & 739,9 & 49,4 \\
Mercure & 0,1 & 0,36 & 0,58 \\
Nickel & 52,0 & 73,2 & 33,2 \\
Plomb & 24 & 99,3 & 53,9 \\
Zinc & 145 & 1220 & 250 \\
$\Sigma$ HAP (série EPA) & 5,86 & 9,58 & 10,25 \\
¿ PCB & $<0,005$ & 0,54 & 0,18 \\
\hline
\end{tabular}

$\Sigma$ HAP, $\Sigma$ PCB : somme des concentrations mesurées.

\section{2 Étape 3 : phase d'analyse de l'évaluation détaillée}

Les résultats des essais de toxicité sur eau interstitielle sont résumés au tableau 3. Aucune toxicité n'a été observée dans l'essai algue. Dans l'essai aigu C. dubia, les pourcentages maximum d'inhibition obtenus en 48 heures sont faibles, et il est impossible de déterminer la Cl50. II en va de même de l'essai «Metplate", où l'inhibition maximale (30\%) est obtenue dans le cas du bief 13. L'essai $C$. dubia en 7 jours n'est pas interprétable tant en ce qui concerne la survie que la reproduction, dans la mesure où l'effet apparent est plus fort pour les concentrations $25 \%$ et $50 \%$ d'eau interstitielle que pour la concentration $100 \%$. B. calyciflorus apparaît comme le plus sensible des organismes testés. L'eau interstitielle du sédiment du bief 2 est la plus toxique pour cette espèce.

Tableau 3 Résultats des bioessais sur eau interstitielle (en \%).

Table 3 Pore water bioassay results (ECx in \%).

\begin{tabular}{|c|c|c|c|c|}
\hline Organismes & Paramètres & B2 & B13 & B22 \\
\hline (Metplate) & CE50 & $\mathrm{nc}$ & $\mathrm{nc}$ & $\mathrm{nc}$ \\
Chiorella vulgaris & CE50 (5 jours) & $\mathrm{nc}$ & $\mathrm{nc}$ & $\mathrm{nc}$ \\
Brachionus calyciflorus & $\mathrm{Cl10}(48 \mathrm{~h})$ & 14,5 & 36,0 & 22,5 \\
Ceriodaphnia dubia & CI50 (48 h) & $\mathrm{nc}$ & $\mathrm{nc}$ & $\mathrm{nc}$ \\
& CE107 jours (survie et reproduction) & $\mathrm{ni}$ & $\mathrm{ni}$ & $\mathrm{ni}$ \\
\hline
\end{tabular}

nc : non calculable; ni : non interprétable. 
Les résultats d'analyse de l'eau interstitielle sont résumés au tableau 4. Les éléments les plus mobiles, appréciés par comparaison avec les teneurs totales dans le sédiment brut, sont l'arsenic (en particulier dans les biefs 2 et 22), le chrome (biefs 13 et 22), et dans une moindre mesure les HAP (bief 13).

Tableau 4 Résultats d'analyse des eaux interstitielles.

Table 4 Pore water chemical concentrations.

\begin{tabular}{|l|c|c|c|}
\hline Bief & $\mathbf{2}$ & $\mathbf{1 3}$ & $\mathbf{2 2}$ \\
\hline pH & 6,8 & 6,9 & 7,2 \\
Conductivité & 471 & 683 & 368 \\
Éléments en trace $\left(\mu \mathrm{g} \cdot \mathrm{L}^{-1}\right)$ & & & \\
Arsenic & 100,0 & 25,0 & 100,0 \\
Cadmium & $<\mathrm{LD}$ & $\mathrm{nm}$ & $<\mathrm{LD}$ \\
Chrome & 0,7 & 0,8 & 27,7 \\
Cuivre & 4,8 & 2,7 & 3,9 \\
Mercure & $<0,2$ & 0,2 & 0,48 \\
Nickel & 2,8 & 1,9 & 4,6 \\
Plomb & 0,9 & 0,05 & 1,3 \\
Zinc & 0,02 & 0,03 & 0,04 \\
$\Sigma$ HAP (série EPA) & 1,29 & 4,34 & 2,00 \\
¿ PCB & $<0,005$ & 0,123 & 0,229 \\
\hline
\end{tabular}

Dans les essais sur chironomes, les critères de validité pour les témoins sont satisfaits (survie $>70 \%$ et poids $>0,5 \mathrm{mg}$ ). Aucun effet significatif n'est observé pour les paramètres de survie. En revanche la croissance pondérale des chironomes est significativement affectée pour les trois biefs (test $t$ de Student, $p=0,05$ ). L'effet sur le poids peut être classé de façon croissante de la manière suivante : bief $2<$ bief $22<$ bief 13 (figure 4). Pour le paramètre survie, le critère de validité de l'essai sur $H$. azteca n'a pu être vérifié ; la diminution de survie observée dans le cas du bief 13 n'est donc pas significative. Aucun effet n'est observable sur la survie des hyalelles dans le cas des deux autres biefs, ni sur la croissance (taille) pour les trois biefs.

Les sédiments testés dans les microcosmes n'ont entraîné que peu ou pas d'effets toxiques sur les organismes pélagiques et benthiques, mis à part des effets génotoxiques (tableau 5). Une deuxième série d'essais, réalisés sans apport de nourriture, a permis d'observer des effets significatifs sur la survie de $H$. azteca et $C$. riparius, ainsi que sur la croissance et l'émergence de $C$. riparius. Le fait que les effets soient plus marqués pour le sédiment du bief 13, qui est d'autre part riche en matière organique, suggère que ces observations sont dues à la présence de substances toxiques apportées par la matière organique utilisée comme nourriture plutôt qu'à l'absence de supplément nutritionnel. Après 15 jours d'exposition, on observe chez les limnées une mortalité comprise entre 4 et $6 \%$, atteignant 15 à $20 \%$ selon l'origine du sédiment (18\% chez les témoins) après 1 mois. Les valeurs de " tail moment " (exprimant le nombre de cassures des brins d'ADN) ont été log-transformées, puis la normalité de la distribution vérifiée par un test Chi carré, de même que l'homogénéité 


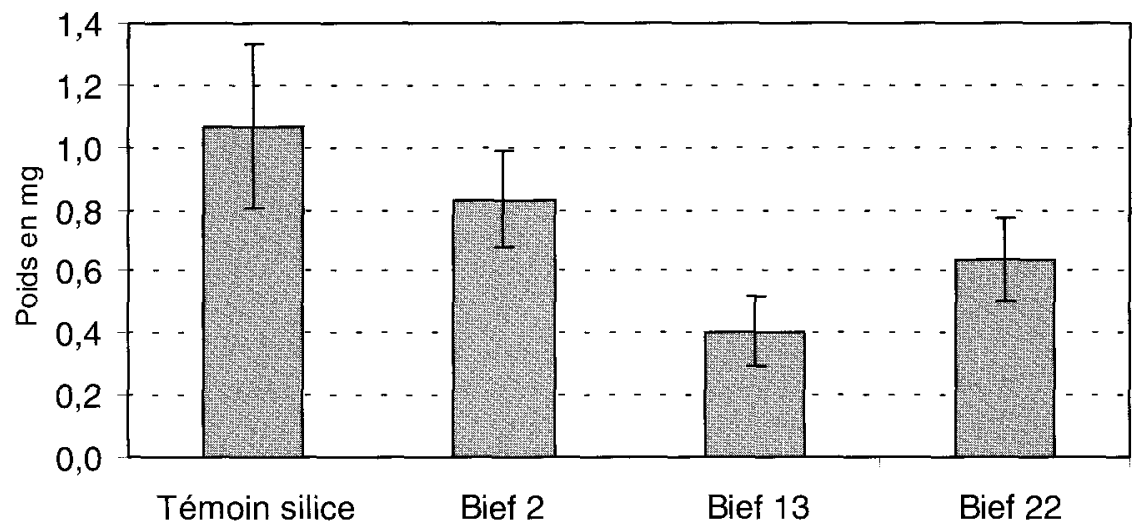

Figure 4 Effet des sédiments à 10 jours sur le poids des chironomes.

Effect of sediments over 10 days on chironomid weights.

de la variance (test de Levenne). Les moyennes géométriques des valeurs de tail moment correspondant aux différentes durées d'exposition sont comparées à l'aide d'un test $t$ au seuil de $5 \%$. Le sédiment du bief 13 exprime une génotoxicité (tail moment augmenté d'un facteur 3 par rapport au témoin) visà-vis des limnées dès 7 jours d'exposition, les dommages à l'ADN persistant après 28 jours d'exposition. Le sédiment du bief 2 est faiblement génotoxique, le niveau de cassures de brins d'ADN étant significatif dans les hémocytes seulement au bout de 28 jours d'exposition. Aucun effet génotoxique n'a été mis en évidence pour le sédiment provenant du bief 22 quelle que soit la durée d'exposition des organismes.

Tableau 5 Résultats des essais en microcosmes.

Table 5 Summary of microcosms observations.

\begin{tabular}{|c|c|c|}
\hline & Avec apport de nourriture & Sans apport de nourriture \\
\hline D. magna & $\begin{array}{l}\text { Effet faiblement significatif sur } \\
\text { la reproduction pour B13 }\end{array}$ & $\begin{array}{l}\text { Effet faiblement significatif sur } \\
\text { la reproduction pour B13 }\end{array}$ \\
\hline L. minor & $\begin{array}{l}\text { Croissance élevée pour tous } \\
\text { les sédiments, pas d'effet }\end{array}$ & $\begin{array}{l}\text { Croissance élevée pour tous } \\
\text { les sédiments, pas d'effet }\end{array}$ \\
\hline \multicolumn{3}{|l|}{ H. azteca } \\
\hline • survie & Pas d'effet & Effet significatif en B13 \\
\hline - croissance & Pas d'effet & Effet significatif en $\mathrm{B} 13$ \\
\hline \multicolumn{3}{|l|}{ C. riparius } \\
\hline - survie & $\begin{array}{l}\text { Pas d'effet en } 20 \text { jours pour } \\
\text { les } 3 \text { sédiments variabilité à J28 }\end{array}$ & effets significatifs en $B 13$ et $B 22$ \\
\hline - croissance & Pas d'effet pour les 3 sédiments & Effets significatifs en B2, B13 et B22 \\
\hline L stanalis & Etret signiricatit en BZ2 & Pas a emergence a $J z I$ en searments \\
\hline L. stagnalis & $\begin{array}{l}\text { Effet génotoxique significatif en } \\
\text { B13 et B22 }\end{array}$ & Non testé \\
\hline
\end{tabular}


Pour les percolats issus des colonnes contenant les sédiments des biefs 2 et 22 , le $\mathrm{pH}$ s'établit très rapidement autour de la valeur d'entrée $(7 \leq \mathrm{pH} \leq 8)$, de même que la conductivité chute rapidement. Les mêmes phénomènes sont observables pour les percolats issus des sédiments du bief 13 , pour lequel il faut attendre un ratio $\mathrm{L} / \mathrm{S}$ de 2 (conductivité) à $4(\mathrm{pH})$ pour qu'une valeur stable soit atteinte. La valeur de 10, affectée au ratio L/S cumulé final paraît donc suffisante pour atteindre un équilibre au niveau des échanges chimiques entre la solution de lixiviation et les sédiments. Pour les percolats du bief 13 , et du bief 22 dans une moindre mesure, les premières fractions collectées présentent des concentrations élevées en métaux (tableau 6), qui décroissent ensuite selon une courbe d'allure exponentielle (figure 5). Les fractions lixiviées restent néanmoins faibles (tableau 6), le maximum étant d'environ $8 \%$ de cadmium extrait du sédiment du bief 13 .

Tableau 6 Concentrations en métaux des premières fractions de percolats et quantité extraite à $\mathrm{L} / \mathrm{S}=10$.

Table 6 Trace elements concentrations in the first percolated fractions and extracted rates at $L / S=10$.

\begin{tabular}{|c|c|c|c|c|c|c|}
\hline & \multicolumn{2}{|c|}{2} & \multicolumn{2}{c|}{13} & \multicolumn{2}{c|}{22} \\
\hline Bief & Cmax & $\begin{array}{c}\text { Fraction } \\
\text { extraite }\end{array}$ & Cmax & $\begin{array}{c}\text { Fraction } \\
\text { extraite }\end{array}$ & $\mathbf{C m a x}$ & $\begin{array}{c}\text { Fraction } \\
\text { extraite }\end{array}$ \\
\hline & $\boldsymbol{\mu g \cdot \mathbf { L } ^ { - 1 }}$ & $\%$ & $\boldsymbol{\mu g} \cdot \mathbf{L}^{-1}$ & $\%$ & $\boldsymbol{\mu g} \cdot \mathbf{L}^{-1}$ & $\%$ \\
\hline $\mathrm{Cd}$ & 1,8 & 0,71 & 294 & 3,46 & 7,1 & 0,16 \\
$\mathrm{Cu}$ & 24,6 & 0,21 & 1332 & 0,3 & 46,3 & 0,19 \\
$\mathrm{Cr}$ & 2,55 & 0,15 & 33,8 & 8,15 & 15,3 & 0,47 \\
$\mathrm{Ni}$ & 15,2 & 0,34 & 1352 & 2,34 & 91,8 & 0,97 \\
$\mathrm{~Pb}$ & 6,82 & 0,14 & 24,9 & 0,04 & 2,35 & 0,1 \\
$\mathrm{Zn}$ & 520 & 0,04 & 119000 & 10,0 & 3750 & 0,4 \\
\hline
\end{tabular}

\section{3 Étape 3 : caractérisation des risques (évaluation détaillée)}

Les trois hypothèses retenues dans l'état actuel de la démarche sont examinées successivement. Dans notre proposition, le rôle de l'évaluateur s'arrête précisément à cet endroit-là. C'est ensuite à l'autorité publique commanditaire de l'évaluation (dans le cas des canaux français) de tirer le bilan de l'évaluation, (a) en décidant si le risque est acceptable ou non, et (b) en prenant les décisions de gestion appropriées.

\subsubsection{H1 : le dépôt de sédiment en gravière ne perturbe pas la structure et les effectifs des peuplements d'invertébrés benthiques}

L'examen de cette hypothèse se fait à l'aide des bioessais sur sédiments et des microcosmes. Les résultats disponibles permettent simplement de classer les sédiments des trois biefs par ordre de danger décroissant : B13>B22 $>$ B2. En effet, le sédiment du bief 13 est celui qui a engendré le plus grand nombre de réponses toxiques dans le panel d'essais. 

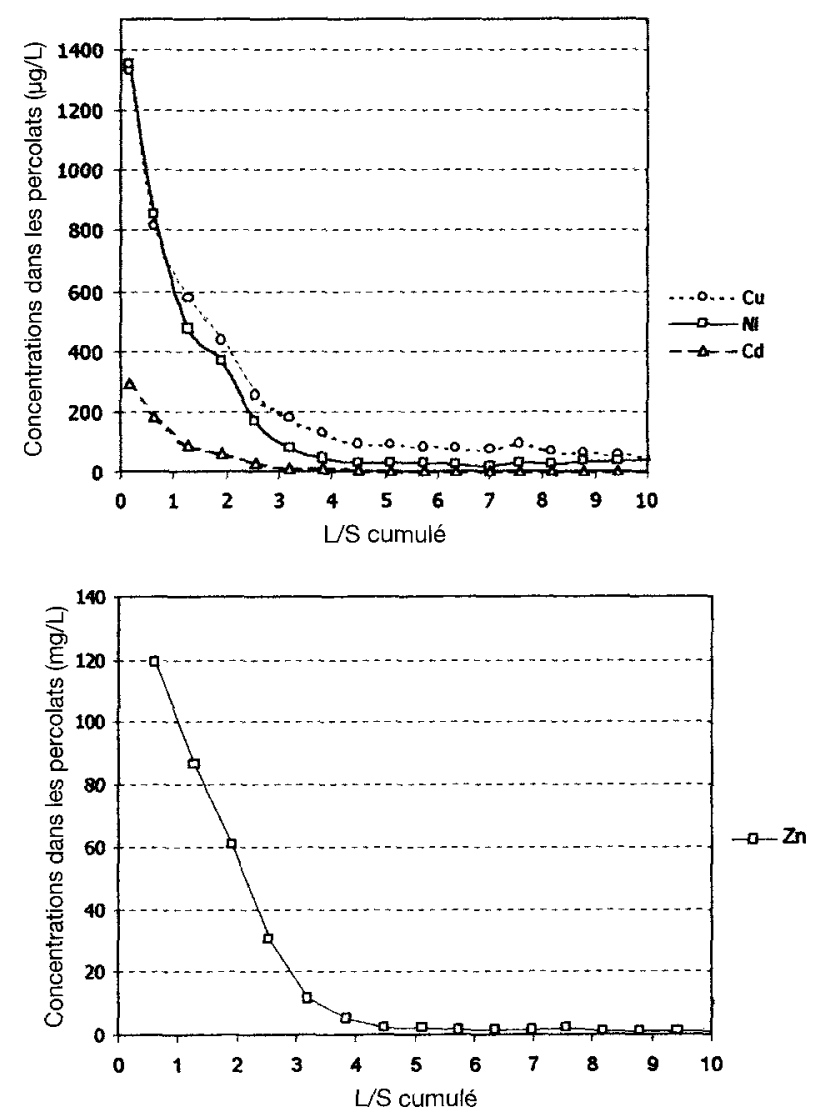

Figure 5 Évolution des concentrations de 4 métaux dans les percolats du bief 13.

Evolution of the concentrations of 4 metals in the percolated fractions from $n^{\circ} 13$ sediment.

\subsubsection{H2 : le dépôt n'entraîne pas d'effets à long terme sur les espèces vivant dans la colonne d'eau}

La caractérisation du risque est faite en comparant le taux de dilution correspondant à un effet donné (CE10 ou Cl10), à la dilution de l'eau interstitielle dans l'eau de la gravière, ici égale à $4 \%\left(1 / N_{E S} / N_{E l}=1 / 25\right)$. Les Cl10 issues de l'essai $B$. calyciflorus (tableau 3 ) sont supérieures à la concentration d'exposition. Pour obtenir une concentration probablement sans effet sur l'environnement, il est couramment appliqué un facteur d'extrapolation, dont la valeur dépend des données considérées (CHAPMAN et al., 1998). Dans le cas de résultats d'essais de toxicité chronique, ce facteur est souvent de 10 . On obtient donc des valeurs de quotient supérieures ou égales à 1 selon les biefs, indiquant en première approximation un risque pour le compartiment aquatique.

Cette conclusion est renforcée par l'observation d'une perturbation de la reproduction des daphnies et de dommages à l'ADN des limnées dans les essais en microcosmes. Le fait que les valeurs des quotients soient relative- 
ment proches de 1 , et les réponses négatives ou non interprétables des autres bioessais aquatiques, devraient normalement inciter à compléter l'analyse de risque pour cette hypothèse. Au cas où le quotient de risque resterait supérieur à 1 après ce deuxième examen, le responsable d'opération aurait encore la possibilité de diminuer le risque en réduisant le volume du dépôt, ce qui aurait mécaniquement pour effet d'augmenter le ratio $V_{E S} N_{E l}$.

\subsubsection{H3 : le dépôt n'entraîne pas de pollution de la nappe alluviale, en particulier dans la perspective de son utilisation pour la production d'eau potable}

Dans ce cas le danger est représenté par les valeurs limites de potabilité d'origine réglementaire (décret $89 / 3$ du 3 janvier 1989 relatif aux eaux destinées à la consommation humaine). Ces valeurs limites sont comparées avec les concentrations maximales dans le percolat, et à l'exposition annuelle représentée par $V_{E N} / M_{S P}$, correspondant pour la gravière étudiée à un ratio $L / S$ de 1,5 (tableau 7). Dans le cas des percolats du bief 13, les concentrations maximales et au ratio L/S de 1,5 du cadmium et de zinc sont supérieures aux limites de potabilité, tant en pointe qu'à un an. Le quotient de risque, pour chacun de ces deux éléments, est largement supérieur à 1. Par conséquent il y a un risque important de pollution de la nappe. Cependant, l'allure des courbes de concentrations dans ces percolats montre que le risque décroît rapidement au-delà d'un an d'exposition. Des mesures de gestion transitoire de ce risque seraient donc envisageables, d'autant plus que les normes de potabilité ont été établies sur la base de durées d'exposition largement supérieures à un an. Les concentrations mesurées dans les percolats issus des sédiments des deux autres biefs restent inférieures aux limites de potabilité.

Tableau 7 Comparaison des concentrations potentielles dans la nappe maximales et au bout d'un an avec les valeurs limites de potabilité (en $\left.\mu \mathrm{g} \cdot \mathrm{L}^{-1}\right)$.

Table $7 \quad$ Maximum and annual groundwater potential concentrations versus drinking water thresholds.

\begin{tabular}{|c|c|c|c|c|c|c|c|}
\hline \multirow{2}{*}{} & \multirow{2}{*}{ Valeurs limites } & \multicolumn{2}{|c|}{ Bief 2 } & \multicolumn{2}{c|}{ Bief 13 } & \multicolumn{2}{c|}{ Bief 22 } \\
\cline { 3 - 8 } & & $\max$ & à 1 an* & $\max$ & à 1 an* & max & à 1 an\# \\
\hline Cadmium & 5 & 1,8 & 0,19 & 294 & 78 & 7,1 & 1,2 \\
Cuivre & 1000 & 24,6 & 6,2 & 1332 & 527 & 46,3 & 15,9 \\
Nickel & 50 & 15,2 & 14,7 & 1352 & 436 & 91,8 & 39,7 \\
Zinc & 5000 & 520 & nd & 119000 & 77000 & 3750 & 230 \\
\hline
\end{tabular}

${ }^{*}$ Concentrations calculées par interpolation linéaire ; ${ }^{\#}$ concentrations mesurées; nm = non mesuré.

Sur les trois hypothèses examinées vis-à-vis des trois sédiments, seul celui du bief 13 pour l'hypothèse relative à la pollution de la nappe alluviale présente donc un risque significatif par rapport aux critères adoptés. Pour ce même sédiment, les deux autres hypothèses examinées ne présentent qu'un risque apparemment faible. Pour les sédiments des deux autres biefs, on a noté un risque faible pour l'hypothèse relative aux effets sur les organismes aquatiques. 


\section{5 - DISCUSSION}

Le résultat obtenu sur les trois biefs à l'issue de l'évaluation détaillée est conforme à ce que l'on pouvait attendre, d'après l'évaluation sommaire préalable : seul le sédiment du bief 13 présentait un score $>0,5$ justifiant la mise en œuvre d'une évaluation détaillée. Avec un score compris entre 0,1 et 0,5 le sédiment du bief 22 aurait été testé avec $C$. riparius et $H$. azteca, conduisant à la décision de ne pas poursuivre par une évaluation détaillée, puisque les effets observés ne sont pas significatifs. Cette décision peut paraître erronée, dans la mesure où un risque lié au relargage de polluants dans la colonne d'eau a été mis en évidence pour les sédiments des trois biefs; le problème est inhérent à la relation entre le score $Q_{P E C m}$ et la toxicité des sédiments, puisque même des sédiments dont le score est < 0,1 peuvent s'avérer toxiques (MACDONALD et al., 2000b). À l'inverse, il n'est pas envisageable de procéder systématiquement à une évaluation détaillée des risques. Le choix des valeurs des seuils relève donc d'un compromis, dont la pertinence ne pourra être évaluée qu'avec un plus grand nombre d'applications.

Concernant le compartiment aquatique, l'hypothèse décrite dans le modèle conceptuel n'est pas suffisante, et doit être complétée. En l'état, on examine simultanément les risques liés à la phase de réalisation du dépôt, pendant laquelle les organismes de la colonne d'eau vont être exposés à l'eau interstitielle du matériau déversé dans la gravière, et ceux engendrés à plus long terme par la désorption des contaminants et leur passage par diffusion dans l'eau de la gravière. Le dispositif expérimental adopté, combinant des bioessais sur eau interstitielle et des microcosmes, permet bien de répondre à ces deux besoins. Deux hypothèses différentes devraient donc figurer dans le modèle conceptuel : (a) lors de la réalisation du dépôt, il ne devra pas être constaté d'effets à court terme sur les populations d'organismes vivants dans la colonne d'eau ; (b) le dépôt ne devra pas entraîner d'effet à long terme sur les organismes de la colonne d'eau. Le point (a) peut être testé à travers l'étude des effets de l'eau interstitielle sur la survie et la reproduction d'organismes aquatiques tels que $C$. dubia, et la croissance d'algues unicellulaires telles que $P$. subcapitata. Le point (b) peut être abordé à l'aide d'essais en microcosmes, comme cela a été fait dans l'étude d'application sur le canal de l'Est.

Le niveau de génotoxicité observé dans les essais en microcosmes, en particulier dans le cas du sédiment du bief 13, paraît élevé si on le compare aux valeurs publiées pour d'autres organismes aquatiques, qu'il s'agisse d'invertébrés tels que les mollusques et les cnidaires, ou de poissons (BELPAEME et al., 1998 ; DEVAUX et al., 1997 ; DEVAUX et al., 1998 ; MITCHELMORE et CHIPMAN, 1998 ; WILSON et al., 1998). L'expression de la génotoxicité, résultante à la fois des dommages à l'ADN et des capacités de réparation de l'organisme (SHUGART et THEODORAKIS 1996), apparaît donc comme un paramètre plus précoce, voire plus sensible que d'autres paramètres écotoxicologiques comme la survie. L'intérêt d'étudier l'intégrité de l'ADN comme biomarqueur de génotoxicité dans le cadre de l'évaluation du risque, en particulier à long terme, réside dans la durabilité de la réponse génotoxique à la fois pour l'organisme et sa descendance (ANDERSON et WILD, 1994 ; DEPLEDGE, 1996 ; DEVAUX et al., 1998 ; WÜRGLER et KRAMERS, 1992). Le paramètre génotoxicité ouvre ainsi la perspective 
de l'analyse de l'impact des contaminants sur la structure génétique des populations d'organismes aquatiques (BICKHAM et al., 2000 ; LARNO et al., 2001). En revanche, il reste à préciser les relations entre modifications de la structure génétique des populations et impacts écologiques, en termes notamment de croissance de ces populations ou de productivité (THEODORAKIS, 2001), ce qu'on peut plus aisément envisager pour des paramètres comme la survie ou la reproduction (CALOW et al., 1997 ; CALOW, 1998).

L'examen de l'hypothèse concernant le compartiment sédimentaire a conduit, dans le cas du CEBS, à considérer que le risque pour les espèces benthiques était faible. Cette conclusion résulte en premier lieu du fait que les sédiments testés étaient modérément contaminés $\left(Q_{\mathrm{PECm}}\right.$ compris entre 0,2 et $1,25)$, mais aussi de la nature des paramètres testés. La survie, en particulier, est un paramètre inadapté à l'estimation des risques à long terme découlant de l'hypothèse posée dans le modèle conceptuel (INGERSOLL et al. in BIDDINGER et al. (1997). Le paramètre croissance, notamment sur $C$. riparius, est reconnu comme plus sensible (GIESY et al., 1988 ; WENTSEL et al., 1977), et est de ce fait plus pertinent dans la perspective d'une évaluation de risque, d'autant plus qu'il rend compte d'une perturbation de la gestion de l'énergie par les organismes, et peut être relié à la reproduction et à la dynamique d'une population (SIBLEY et al., 1997).

Les résultats des bioessais $C$. riparius et $H$. azteca, de même que ceux des essais en microcosmes, sont par ailleurs potentiellement biaisés par les apports de nourriture en cours d'essai, apports qui permettent aux organismes de compenser partiellement les effets toxiques (POSTMA et al., 1994), ou qui diminuent l'exposition par dilution (PASCOE et al., 1990), ou encore l'augmentent en modifiant l'élimination des substances par les organismes (LANDRUM et al., 1992, cité par RISTOLA et al., 1999). D'autre part, l'exposition des organismes benthiques à des métaux comme le zinc, le cadmium ou le nickel se fait au moins autant par voie trophique que respiratoire ou transmembranaire (LEE et al., 2000 ; LUOMA, 1989 ; LUOMA et LUOMA, 1997). Ce biais pourrait donc conduire à sous-estimer les effets ; c'est effectivement ce que nous avons observé en comparant les microcosmes non supplémentés en nourriture aux microcosmes standard. Inversement, l'absence d'apport de nourriture augmente fortement la variabilité des réponses des sédiments contrôles, et la proportion de sédiments apparemment toxiques (ANKLEY et al., 1994). ANKLEY et al. (1994), de même que RISTOLA et al. (1999) préconisent donc de réaliser les bioessais avec des apports de nourriture réduits. II faut donc dans un premier temps chercher à établir la relation entre la nourriture disponible et la croissance. Dans un second temps, il faudrait chercher à minimiser les interférences entre nourriture apportée et exposition, la difficulté majeure étant qu'elles dépendent en partie de la substance chimique en cause (HARKEY et al., 1997 ; HARKEY et al., 1994).

L'hypothèse concernant la nappe alluviale s'est avérée la plus sensible des trois hypothèses examinées. La désorption suivie par le transport de contaminants apparaît comme un phénomène durable dans le cas du bief 13 (figure 5), et la stabilité des concentrations n'est pas encore atteinte lorsque le ratio L/S atteint la valeur du ratio d'exposition annuelle. La fraction exportée pendant la durée de l'essai ne représente au maximum que $10 \%$ environ de la charge totale. Néanmoins, le risque le plus élevé se situe dans les premiers mois du dépôt, puisque les concentrations les plus élevées dans les percolats corres- 
pondent aux premières fractions collectées. Un des principaux biais de l'approche en colonne réside dans le préconditionnement (séchage) que l'on doit faire subir au sédiment avant l'expérience, qui modifie la matrice tant chimiquement que structurellement. Une adaptation de ce protocole à des matériaux très humides doit être envisagée.

L'évaluation de l'exposition dépend beaucoup des ratios caractéristiques $V_{E S} / V_{S}, V_{E S} N_{E I}$ et $V_{E N} / M_{S P}$. Les deux premiers sont relativement simples à estimer, et permettent d'obtenir une estimation assez robuste du risque. La détermination du troisième ratio $\left(V_{E N} / M_{S P}\right)$ est plus délicate, et requiert des données moins directement accessibles, en particulier la vitesse de la nappe. II doit dans l'absolu être déterminé au cas par cas afin d'ajuster la vitesse à laquelle l'expérience doit être menée dans la colonne afin d'obtenir des temps de contact entre l'eau et les sédiments identiques au cas du terrain et afin d'affiner le pas de temps pour la collecte des fractions. De plus, ce ratio est le seul des trois à prendre explicitement le temps en considération. S'agissant d'une valeur annuelle, il permet par comparaison avec les ratios L/S cumulés de procéder à une estimation des risques de pollution de la nappe pendant les premières années suivant le dépôt. Si l'on peut admettre une certaine approximation dans la détermination des ratios $\mathrm{V}_{\mathrm{ES}} \mathrm{N}_{\mathrm{S}}$ et $\mathrm{V}_{\mathrm{ES}} \mathrm{V}_{\mathrm{El}}$, celle du ratio $V_{E N} / M_{S P}$ doit être conduite avec d'autant plus de rigueur que le risque de pollution de la nappe alluviale sera probablement souvent plus critique que les autres risques abordés dans le scénario actuel.

D'autres approches d'évaluation des matériaux de dragage ont été proposées, notamment par le corps des ingénieurs de l'armée américaine (USACE) en collaboration avec l'Agence fédérale de protection de l'environnement (USEPA) (US-EPA et USACE, 1998a, b). Le schéma développé est un protocole par étapes, basé sur des moyens d'investigation similaires (analyse chimique, bioessais, essais de comportement), sans se réclamer explicitement d'une démarche d'évaluation des risques, du moins dans les 3 premières étapes (Tier 1 à 3). Une première différence importante vient de ce que les dépôts en eau sont dans ce cas essentiellement des dépôts en milieu lacustre ouvert, et soumis à des courants, ce qui n'est pas le cas du scénario que nous avons étudié. Plusieurs différences méthodologiques peuvent également être relevées Dans l'approche USEPA-USACE, des critères physiques comme la granulométrie servent à exclure certains matériaux de l'évaluation. Bien que les concentrations totales soient mesurées dans les sédiments à l'étape 2, aucun critère de qualité (ou seuil de danger) n'est utilisé, contrairement à l'étape d'évaluation sommaire de notre protocole. Les seuls critères de qualité chimique utilisés sont les critères de qualité de l'eau, et ils ont une importance réduite par rapport aux résultats des bioessais appliqués à l'étape 3 . De plus, dans l'approche USEPA-USACE, on se réfère à des valeurs absolues (\% de mortalité, poids moyen de $C$. riparius etc.) assimilables à des seuils de danger, tandis que dans notre schéma ceux-ci n'interviennent qu'à l'étape préliminaire d'évaluation simplifiée. La prise en compte de l'exposition ne nous semble pas ajouter de difficulté majeure au stade de l'acquisition des données, à l'exception de l'évaluation de la vitesse de la nappe alluviale. Elle permet en revanche de prendre en considération les caractéristiques du milieu récepteur dans la décision de gestion. Cette prise en compte intervient dans la démarche USEPAUSACE sous forme d'un modèle de dispersion dans l'eau. 


\section{6 - CONCLUSION}

Le schéma que nous avons développé devrait être validé avant d'être préconisé à titre réglementaire ou dans les schémas opérationnels des organisations en charge de la gestion des cours d'eau. Cette validation passera nécessairement par l'étude in situ de communautés benthiques, simultanément aux analyses chimiques et aux essais de toxicité inclus dans le protocole (POREBSKI et al., 1999). Ce type d'approche est communément désigné sous le terme "TRIAD ", et a souvent été employé y compris dans des étapes d'évaluation préalables à des opérations de dragage (ANDERSON et al., 2001 ; BESSER et al., 1996 ; CANFIELD et al., 1996 ; CHAPMAN, 1990). Ce terme de «TRIAD » désigne toutefois non seulement la démarche d'investigation proprement dite, associant analyses chimiques, bioessais et étude des communautés, mais également parfois l'expression des résultats et leur agrégation. Ce deuxième aspect, au demeurant non retenu par des auteurs comme POREBSKI et al. (1999), ne nous paraît cependant pas pertinent dans la perspective d'une validation du schéma, dans la mesure où l'objectif de la validation serait principalement de vérifier le caractère prédictif des bioessais vis-à-vis des populations benthiques et pélagiques plutôt que d'intégrer un ensemble de données dans une expression synthétique.

Cette étude a permis de montrer qu'il est possible d'évaluer des risques pour les écosystèmes aquatiques engendrés par un dépôt sous eau de matériaux de dragage, à l'aide de moyens d'investigation écotoxicologiques accessibles, et partiellement normalisés. Pour autant, le scénario présenté peut et doit encore être amélioré dans plusieurs directions. II convient notamment de vérifier, par d'autres études in situ, si la batterie d'essais retenus ne peut pas être allégée et sa pertinence améliorée sur la base des variables biologiques étudiées et des voies d'exposition des organismes. Enfin, les risques liés aux transferts trophiques devraient également être inclus dans le scénario.

\section{REMERCIEMENTS}

Ce travail a reçu le soutien de la Direction de la recherche et des affaires scientifiques et techniques (DRAST) du ministère de l'Équipement et des Transports (France), ainsi que de Voies navigables de France. II a bénéficié des réflexions d'un comité de pilotage incluant également Mme G. GOLASZEWSKI (Direction de l'eau du ministère de l'Aménagement du Territoire et de l'Environnement), M. C. ALZIEU (Ifremer), M. C. THOMAS (DIREN Nord-Pas-de-Calais) et M. H. VERHAEGHE (Agence de l'eau Artois-Picardie). 


\section{RÉFÉRENCES BIBLIOGRAPHIQUES}

ANDERSON B.S., J.W. H., PHILIPPS B.M., FAIREY R., ROBERTS C.A., OAKDEN J.M., PUCKETT H.M., STEPHENSON M., TJEERDEMA R.S., LONG E.R., WILSON C.J., LYONS J.M., 2001. Sediment quality in Los Angeles Harbor, États-Unis: a TRIAD assessment. Environ. Toxicol. Chem., 20, 359-370.

ANDERSON S.L., WILD G.C., 1994. Linking genotoxic responses and reproductive success in ecotoxicology. Environ. Health Perspect., 102, 9-12.

ANKLEY G.T., BENOIT D.A., BALOGH J.C., REYNOLDSON T.B., 1994. Evaluation of potential confounding factors in sediment toxicity tests with three freshwater benthic invertebrates. Environ. Toxicol. Chem., 13, 627-635.

BABUT M., BREUZIN C., LASCOMBE C., PEREIRA-RAMOS L., 1999. Sediment quality assessment of three rivers and streams in France: the Moselle, the Rhone and the Seine. International Symposium, Sediment Quality Assessment Berlin, 20-22 avril 1999.

BELPAEME K., COOREMAN K., KIRSCHVOLDERS, 1998. Development and validation of the in vivo alkaline comet assay for detecting genomic damage in marine flatfish. Mutat. Res., 415, 167184.

BESSER J.M., GIESY J.P., KUBITZ J.A., VERBRUGGE D.A., COON T.G., BRASELTON W.E., 1996. Assessment of sediment quality in dredged and undredged areas of the Trenton Channel of the Detroit River, Michigan, États-Unis, using the Sediment Quality Criteria. J. Great Lakes Res. , 22, 683-696.

BICKHAM J.W., SANDHU S., HEBERT P.D.N., CHIKI L., ATHWAL R., 2000. Effects of chemical contaminants on genetic diversity in natural populations: implications for biomonitoring and ecotoxicology. Mutat. Res., 463, 33-51.

BIDDINGER G.R., DILLON T., INGERSOLL C.G., 1997. Ecological risk assessment of contaminated sediments, SETAC Press États-Unis.

BITTON G., JUNG K., KOOPMAN B., 1993. Evaluation of a microplate assay specific for heavy metal toxicity, Archives of Envi- ronmental Contamination and Toxicology, 27, 25-28.

CALLIER L., CHARBONNIER P., 2000. Remblaiement de gravières, carrières et plans d'eau - Critères d'appréciation des demandes d'autorisation et contrôles à mettre en oeuvre. Application en Lorraine et Champagne-Ardennes pour la partie du bassin Rhin-Meuse la concernant. Report. BRGM, BRGM/RP-50111-FR, 61.

CALOW P., 1998. Ecological risk assessment: risk for what? How do we decide? Ecotoxicol. Environ. Safety, 40, 15-18.

CALOW P., SIBLY R.M., FORBES V., 1997. Risk assessment on the basis of simplified life-history scenarios. Environ. Toxicol. Chem., 16, 1983-1989.

CANFIELD T.J., DWYER F.J., FAIRCHILD J.F., HAVERLAND P.S., INGERSOLL C.G., KEMBLE N.E., MOUNT D.R., LA POINT T.W., BURTON G.A., SWIFT M.C., 1996. Assessing contamination in Great Lakes sediments using benthic invertebrate communities and the sediment quality triad approach. $J$. Great Lakes Res., 22, 565-583.

CASTANY G., 1982. Principes et méthodes de I'hydrogéologie. Ed Dunod, Paris. $236 \mathrm{p}$.

CHAPMAN P.M., 1990. The sediment quality triad approach to determining pollutioninduced degradation. Sci. Tot. Environ., 97-98, 815-825.

CHAPMAN, P. M., FAIRBROTHER A., BROWN D., 1998. A critical evaluation of safety (uncertainety) factors for ecological risk assessment. Environ. Toxicol. Chem., 17 (1), 99-108.

CLÉMENT B., CADIER C., 1998. Development of a new laboratory freshwater/ sediment microcosm test Ecotoxicology, 7, 279-290.

DEPLEDGE M.H., 1996. Genetic ecotoxicology: an overview. J. Exp. Mar. Biol. Ecol., 200, 57-66.

DEVAUX A., PESONEN M., MONOD G., 1997. Alkaline comet assay in rainbow trout hepatocytes. Toxicol. Vitro, 11, 71-79.

DEVAUX A., FLAMMARION P., BERNARDON V., GARRIC J., MONOD G., 1998. 
Monitoring of the chemical pollution of the river Rhône through measurement of DNA damage and cytochrome P4501A induction in chub (Leuciscus cephalus). Mar. Environ. Res., 46, 257-262.

EPA, 1994. Methods for measuring the toxicity and bioaccumulation of sedimentassociated contaminants with freshwater invertebrates. Testing manual Report. U.S. Environment Protection Agency, Duluth, États-Unis, EPA-600/R94/024, 133.

EPA, 1997a. The incidence and severity of sediment contamination in surface waters of the United States. Volume 1. National sediment quality survey. Report. EPA 823/R-97/006.

EPA, 1997b. The incidence and severity of sediment contamination in surface waters of the United States. Volume 2. Data Summaries for areas of probable concern. Report. EPA-823/R-97/007.

EPA, 1998. Guidelines for Ecological Risk Assessment Report. US Environment Protection Agency, Washington DC, États-Unis, EPA-630/R-95/002F, 114.

GARRIC J., MIGEON B., VINDIMIAN E., 1990. Lethal effects of draining on brown trout. A predictive model based on field and laboratory studies. Wat. Res., 24, 59-65.

GIESY J.P., GRANEY R.L., NEWSTED J.L., ROSIU J.L., BENDA A., KREIS R.G., HORVATH F.J., 1988. Comparison of three sediment bioassay methods using Detroit River sediments. Environ. Toxicol. Chem., 7, 483-498.

HARKEY G.A., DRISCOLL S.K., LANDRUM P.F., 1997. Effect of feeding in 30-day bioaccumulation assays using Hyalella azteca in fluoranthene-dosed sediment. Environ. Toxicol. Chem., 16, 762-769.

HARKEY G.A., LANDRUM P.F., KLAINE S.J., 1994. Preliminary studies on the effect of feeding during whole sediment bioassays using Chironomus riparius larvae. Chemosphere, 28, 597-606.

IMBERT T., PY C., DUCHENE M., 1998. Enlèvement des sédiments - Guide méthodologique - Faut-il curer ? Pour une aide à la prise de décision. Report. Pôle de compétence sur les sites \& sols pollués Nord-Pas-de-Calais. Agence de l'eau Artois-Picardie, Douai, FRA, 161.
ISNARD P., FLAMMARION P., ROMAN G., BABUT M., BASTIEN P., BINTEIN S., ESSERMEANT L., FERARD J.F., GALLOTTI-SCHMITT S., SAOUTER E., SAROLI M., THIEBAUD H., TOMASSONE R., VINDIMIAN E., 2001. Statisti$\mathrm{cal}$ analysis of regulatory ecotoxicity tests. Chemosphere, 45, 659-669.

KEMBLE N.E., BRUNSON E.L., CANFIELD T.J., DWYER F.J., INGERSOLL C.G., 1998. Assessing sediment toxicity from navigational pools of the upper Mississippi river using a 28-day Hyalella azteca test. Archives of Environmental Contamination and Toxicology, 35, 181-190.

LARNO V., LAROCHE J., LAUNEY S., FLAMMARION P., DEVAUX A., 2001. Responses of chub (Leuciscus cephalus) populations to chemical stress, assessed by genetic markers, DNA damage and cytochrome P4501A induction. Ecotoxicology, 10, 145-158.

LASIER P.J., WINGER P.V., BOGENRIEDER K.J., 2000. Toxicity of manganese to Ceriodaphnia dubia and Hyalella azteca. Arch. Environ. Contam. Toxicol., 38, 298304.

LEE B.G., GRISCOM S.B., LEE J.S., CHOI H.J., KOH C.H., LUOMA S., FISHER N.S., 2000. Influences of dietary uptake and reactive sulfides on metal bioavailability from aquatic sediments. Science, 287, 282-284.

LUOMA S.N., 1989. Can we determine the biological availability of sediment-bound trace elements? Hydrobiol., 176/177, 379-396.

LUOMA S.N., N. F., 1997. Uncertainties in assessing contaminant exposure from sediments. In: INGERSOLL C.G., DILLON T., BIDDINGER G.R. (ed.), ECOlogical risk assessment of contaminated sediments, 211-237.

MACDONALD D.D., DIPINTO L.M., FIELD J., INGERSOLL C.G., LONG E.R., SWARTZ R.C., 2000a. Development and evaluation of consensus-based sediment effect concentrations for polychloro-biphenyls (PCBs). Environ. Toxicol. Chem., 19, 1403-1413.

MACDONALD D.D., INGERSOLL C.G., BERGER T.A., 2000b. Development and evaluation of consensus-based sediment quality guidelines for freshwater ecosystems. Arch. Environ. Contam.Toxicol., 39, 20-31. 
MITCHELMORE C.L., CHIPMAN J.K., 1998. DNA strand breakage in aquatic organisms and the potential value of the comet assay in environmental monitoring. Mutat. Res., 399, 135-147.

PASCOE D., BROWN A.F., EVANS B.M.J., MCKAVANAGH C., 1990. Effects and fate of cadmium during toxicity tests with Chironomus riparius - the influence of food and artificial sediment. Archives of Environmental Contamination and Toxicology, 19, 872-877.

POREBSKI L.M., DOE K.G., ZAJDLIK B.A., LEE D., POCKLINGTON P., OSBORNE J.M., 1999. Evaluating the techniques for a tiered testing approach to dredged sediment assessment- a study over a metal concentration gradient. Environ. Toxicol. Chem., 18, 2600-2610.

POSTMA J.F., BUCKERT-DE J., M.C., STAATS N., DAVIDS C., 1994. Chronic toxicity of cadmium to Chironomus riparius (Diptera: Chironomidae) at different food levels. Archives of Environmental Contamination and Toxicology, 26, 143148.

RISTOLA T., PELLINEN J., RUOKOLAINEN M., KOSTAMO A., KUKKONEN J.V.K., 1999. Effect of sediment type, feeding level, and larval density on growth and development of a midge (Chironomus riparius). Environ. Toxicol. Chem., 18, 756-764.

SIBLEY P.K., BENOIT D.A., ANKLEY G.T., 1997. The significance of growth in Chironomus tentans sediment toxicity tests: relationship to reproduction and demographic endpoints. Environ. Toxicol. Chem., 16, 336-345.

SINGH N.P., McCOY M.T., TICE R.R., SCHNEIDER E.L., 1988. A simple technique for quantitation of low levels of DNA damage in individual cells. Experimental Cell Research, 175, 184-191.

SHUGART L.R., THEODORAKIS C., 1996. Genetic ecotoxicology: the genotypic diversity approach. Comp. Biochem. Physiol., 113C, 273-276.
THEODORAKIS C.W., 2001. Integration of genotoxic and population genetic endpoints in biomonitoring and risk assessment. Ecotoxicology, 10, 245-256.

TICE R.R., AGURELL E., ANDERSON D., BURLINSON B., HARTMANN A., KOBAYASHI H., MIYAMAE Y., ROJAS E., RYU J.-C., SASAKI Y.F., 2000. Single cell gel/comet assay: guidelines for in vitro and in vivo genetic toxicology testing. Environ. Molec. Mutagen., 35, 206-221.

US-EPA, USACE, 1994. Evaluation of dredged material proposed for discharge in waters of the United States. Testing Manual (Draft) Report. US Environment Protection Agency, US Army Corps of Engineers., Duluth, États-Unis, EPA823/B-94/002, 172.

US-EPA, USACE, 1998a. Evaluation of dredged material proposed for discharge in waters of the United States. Testing manual Report. US Environment Protection Agency - U.S. Army Corps of Engineers, Washington DC, États-Unis, EPA-823/B-98/004.

US-EPA, USACE, 1998b. Great Lakes dredged material testing and evaluation manual. Report. US Environmental Protection Agency/US Army Corps of Engineers, 62 .

WENTSEL R., MCINTOSH A., ATCHINSON G., 1977. Sublethal effects of heavy metal contaminated sediments on midge larvae (Chironomus tentans). Hydrobiol., 56, 153-156.

WILSON J.T., PASCOE P.L., PARRY J.M., DIXON D.R., 1998. Evaluation of the comet assay as a method for the detection of DNA damage in the cells of a marine invertebrate Mytilus edulis $L$. (Mollusca: Pelecypoda). Mutat. Res., 399, 87-95.

WÜRGLER F.E., KRAMERS P.G.N., 1992. Environmental effects of genotoxins (eco-genotoxicology). Mutagenesis, 7, 321-327. 